\title{
Correlation of cervical sagittal alignment parameters on full-length spine radiographs compared with dedicated cervical radiographs
}

\author{
Leah Y. Carreon ${ }^{1 *}$, Casey L. Smith², John R. Dimar $\|^{1}$ and Steven D. Glassman ${ }^{1}$
}

\begin{abstract}
Background: Radiographic parameters to evaluate the cervical spine in adult deformity using 36-inch films have been proposed. While 36-inch films are used to evaluate spinal deformity, dedicated cervical films are more commonly used to evaluate cervical spine pathology. The purpose of this study is to determine correlations between sagittal measures from a dedicated cervical spine radiographs and 36-inch spine radiographs.

Methods: Patients who had standing cervical and 36-inch radiographs within four weeks of each other were identified. On separate occasions, the following measures were determined: C0-C2, C0-C7, C1-C2 and C2-C7 sagittal Cobb angles; T1 slope; chin-brow-vertical angle (CBVA), C1-C7 sagittal vertical axis (SVA), C2-C7SVA, center of gravity-C7 sagittal vertical axis (COG-C7SVA). Paired t-tests and correlation analyses were done between parameters from the cervical and the 36-inch film.

Results: Radiographic measurements were collected on 40 patients (33 females and 7 males, mean age of $48.9 \pm 14.5$ years). All correlations were statistically significant at $p<0.001$. C0-C2 Cobb had the strongest correlation $(r=0.81)$ and C2-C7 Cobb had the weakest ( $r=0.62)$. Among sagittal balance parameters, COG-C7SVA had the weakest correlation ( $r=0.42)$ and C1-C7SVA $(r=0.64)$ and the C2-C7SVA $(r=0.65)$ had strong correlations. The T1 slope and the CBVA had correlation coefficients of 0.74 and 0.91 , respectively. There was no statistically significant difference in measures taken from the cervical film and 36-inch film, except for the C0-C7 Cobb $(p=0.000)$ with a measurement difference of $7^{\circ}$ and the T1 tilt $(p=0.000)$ with a measurement difference of $5^{\circ}$.

Conclusion: Except for COG-C7 SVA, strong correlations between most cervical spine parameters taken from a dedicated cervical film and those taken from a 36-inch film were seen. 36-inch radiographs provide a reasonable estimation of cervical sagittal spine parameters and may obviate the need for a dedicated cervical spine radiograph.
\end{abstract}

Keywords: Cervical spine, Adult spinal deformity, Sagittal parameters

\section{Background}

Over the past 10 years, there has been an increased focus on the evaluation and treatment of adult scoliosis [1-3]. Several studies have examined the complexity of adult scoliosis patients, based in part on the interaction of the deformity with the normal aging processes of the spine [2-7]. The intersection between degeneration and

\footnotetext{
* Correspondence: leah.carreon@nortonhealthcare.org

${ }^{1}$ Norton Leatherman Spine Center, 210 East Gray Street, Suite 900, Louisville, KY 40202, USA

Full list of author information is available at the end of the article
}

deformity is most evident in relation to the lumbar spine. Typically, assessment of adult scoliosis patients involves evaluation of both the primary deformity and the lumbar spine $[4,8,9]$. Even when managing a primary thoracic curve, treatment decisions may revolve around the impact of any potential surgery on the unfused lumbar levels [4, 8-11].

Recently, attention has been directed to the impact of adult scoliosis or scoliosis treatment on the cervical spine [12-20]. Several authors have proposed a set of standardized radiographic parameters [21] to help evaluate the 
cervical spine in patients with adult spinal deformity using full-length 36-inch radiographs. While this is the standard radiograph used to evaluate spinal deformity, dedicated cervical spine radiographs are more commonly used to evaluate cervical spinal pathology.

With the need to limit costs and exposure to radiation, there is a need to determine whether a separate cervical spine radiograph, aside from the long 36-inch radiograph, is necessary to evaluate the sagittal parameters of the cervical spine. Recent studies have reported a higher incidence of cancer in adolescent idiopathic scoliosis patients who have had multiple radiographs [22]. As the effect of radiation exposure is cumulative, decreasing the number of radiographs taken over an individual's lifetime, regardless of age, should be considered. The purpose of this study is to determine whether there is a correlation between sagittal measures of the cervical spine taken from the 36 -inch spine radiographs and sagittal measures of the cervical spine taken from cervical spine radiographs.

\section{Methods}

From a multi-surgeon spine specialty clinic, patients who had a 36-inch spine radiograph as well as a separate standing cervical spine radiograph within four weeks of each other were identified. All radiographs were taken using a Picture Archiving and Communication System (PACS). All 36-inch standing radiographs were taken with the beam centered at the thoracic area in order for both femoral heads and the cervical spine to be visible. All 36-inch spine films were taken in the "clavicle" position [23]. The "clavicle" position has the patient full flex both elbows with the hands in a relaxed fist, wrists flexed, hands are centered in the supraclavicular fossae, midway between the suprasternal notch and acromion, passively flexing the humerus forward. This position has been standard at our center since 2002. All dedicated cervical spine films were taken with the beam centered at C4 approximately the level of the angle of the mandible.

From the de-identified 36-inch and cervical spine radiographs, the following radiographic measures [21] were determined: occiput-C2 (C0-C2), occiput-C7 ( $\mathrm{C} 0$ C7), $\mathrm{C} 1-\mathrm{C} 2$ and $\mathrm{C} 2-\mathrm{C} 7$ sagittal Cobb angles (Fig. 1); T1 slope; chin-brow vertical angle (CBVA), C1-C7 sagittal vertical axis (C1-C7 SVA), C2-C7 sagittal vertical axis (C2-C7 SVA) and center of gravity- sagittal vertical axis (COG-C7 SVA). The measurements for the 36-inch radiographs and cervical spine radiographs were done on separate sessions by a single-observer. Standard demographic data including age and sex were also collected.

T1 slope is the angle between the angle between a horizontal line and the upper end plate of T1. Sagittal plane translation of the cervical spine is measured through the C7 SVA, which is a plumb line in line with the posterior superior aspect of C7. C1-C7 SVA is the distance between a plumb line dropped from the anterior tubercle of $\mathrm{C} 1$ and the C7-SVA. C2-C7 SVA is the distance between a plumb line dropped from the centroid of $\mathrm{C} 2$ (or odontoid) to the C7 SVA. COG-C7 SVA is the distance between a plumb line dropped from the anterior portion of the external auditory canal to the C7 SVA.

Paired t-tests and correlation analyses were performed between the sagittal radiographic parameter as measured

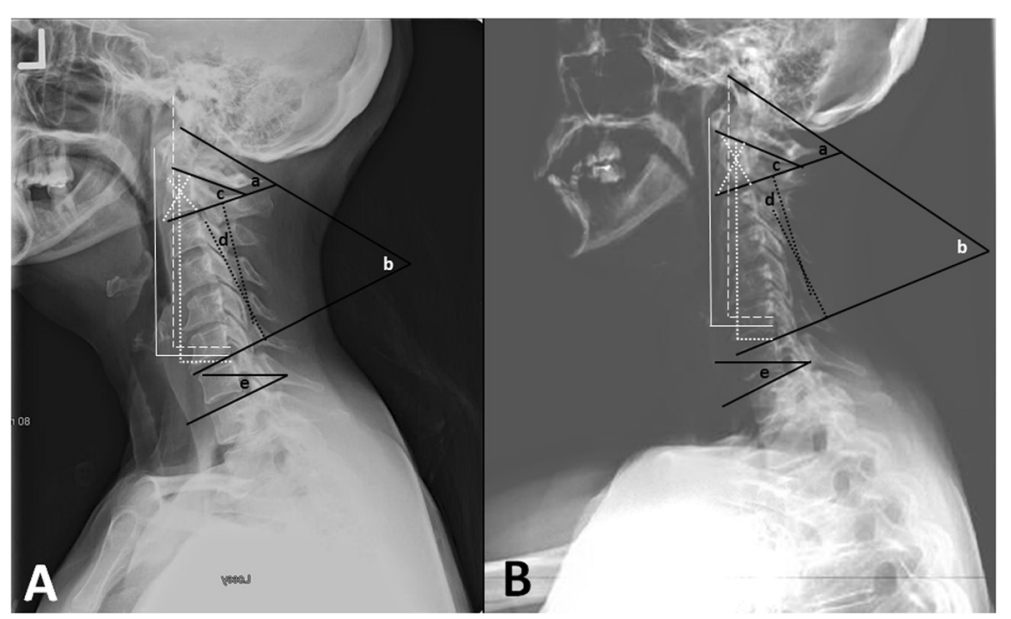

Fig. 1 a Cervical lateral radiograph; b Detail of 36-inch lateral radiograph showing measurements (a) Occiput-C2 sagittal Cobb angle, (b) OcciputC7 sagittal Cobb angle, (c) C1-C2 sagittal Cobb angle, (d) C2-C7 sagittal Cobb angle, (e) T1 tilt. Horizontal solid white line: C1-C7 Sagittal Vertical Axis - distance between plumb line dropped from anterior tubercle of $\mathrm{C} 1$ and posterior superior corner of C7; Horizontal white dotted line: $\mathrm{C2}-\mathrm{C} 7$ Sagittal Vertical Axis - distance between plumb line dropped from centroid of C2 and posterior superior corner of C7; White dashed line: Center of Gravity-C7 Sagittal Vertical Axis_-distance between plumb line dropped from anterior margin of external auditory meatus and posterior superior corner of $\mathrm{C} 7$ 
Table 1 Correlation coefficients between radiographic parameters measured on the 36-inch radiograph and the cervical spine radiograph. All correlations were statistically significant at $p<0.001$

\begin{tabular}{lc}
\hline Radiographic parameter & Correlation coefficient \\
\hline Occiput-C2 Sagittal Cobb angle & 0.808 \\
Occiput-C7 Sagittal Cobb angle & 0.678 \\
C1-C2 Sagittal Cobb angle & 0.639 \\
C2-C7 a Sagittal Cobb angle & 0.620 \\
T1 tilt & 0.742 \\
C2-C7 Sagittal Vertical Axis & 0.653 \\
C1-C7 Sagittal Vertical Axis & 0.635 \\
Center of Gravity-C7 Sagittal Vertical Axis & 0.415 \\
Chin-brow-vertical angle & 0.911 \\
\hline
\end{tabular}

on the cervical spine radiograph and corresponding paired radiographic parameter on the 36 -inch radiograph. Correlation coefficients between 0.60 and 0.80 indicate a marked degree of correlation; while coefficients between 0.80 and 1.00 indicate robust correlations [24].This study was reviewed and approved by the University of Louisville Institutional Review Board (13.0757) and the Norton Healthcare Office of Research Administration (13-N0234).

\section{Results}

Radiographic measurements were collected on 40 patients. There were 33 females and 7 males with a mean age of $48.9 \pm 14.5$ years. All correlations were statistically significant at $p<0.001$ (Table 1). All sagittal Cobb measures showed a marked correlation. The $\mathrm{C} 0-\mathrm{C} 2$ sagittal Cobb had the strongest correlation $(r=0.81)$ and the C2-C7 sagittal Cobb had the weakest (0.62). Among the sagittal balance parameters, the COG-C7 SVA had the weakest correlation $(r=0.42)$, and the C1-C7 SVA $(r=0.64)$ and the C1-C7 SVA $(r=0.65)$ had strong correlations. The T1 slope and the CBVA had correlation coefficients of 0.74 and 0.91 , respectively. Paired t-tests showed that there was no statistically significant difference in the measures taken from the cervical radiograph and 36-inch radiograph (Table 2), except for the occiput-C7 sagittal Cobb angle $(p=0.000)$ with a measurement difference of $7^{\circ}$ and the T1 tilt $(p=0.000)$ with a measurement difference of $5^{\circ}$.

\section{Discussion}

The importance of restoration of sagittal spinal alignment on treatment effectiveness and clinical outcomes during deformity correction has been the subject of numerous studies $[9,25,26]$. Most of these studies focus on the importance of the restoration of lumbar lordosis and its relation to the pelvic incidence $[8,9$, $24]$. Only recently has the role of cervical sagittal measures in outcomes for spine deformity been studied [12-20].

A study by Smith et al. [27] showed that surgical correction of positive sagittal spinopelvic malalignment results in improvement of abnormal cervical hyperlordosis. In contrast, Oh et al. [16] showed that cervical lordosis is commonly seen in patients with adult spinal deformity and does not appear to normalize after thoracic corrective surgery. Patients with substantial compensatory cervical lordosis have been shown to be at increased risk of sagittal spinal pelvic malalignment [17]. Also, a study on adult spinal deformity patients showed that a more proximal upper end vertebra was predictive of the presence of neck pain complaints [28].

Thus, with the increasing evidence of the role of cervical sagittal parameters on clinical outcomes and disability in adult spinal deformity along with the need to control costs and limit patient exposure to radiation, this study was undertaken to determine whether a separate cervical spine radiograph, aside from the long 36inch radiograph, is necessary to evaluate the sagittal parameters of the cervical spine. Data from this study showed that, except for COG-C7 SVA, there were strong correlations between most cervical spine parameters taken from a dedicated cervical spine radiograph and those taken from a 36-inch radiograph. In addition, measures taken from the cervical radiograph and 36-inch

Table 2 Mean (standard deviation) of radiographic parameters as measures on the 36-inch and cervical spine radiograph

\begin{tabular}{|c|c|c|c|c|}
\hline Radiographic parameter & 36-inch & Cervical & $p$-value & Difference \\
\hline Occiput-C2 Sagittal Cobb angle (degrees) & $-41.89(9.74)$ & $-43.30(8.70)$ & 0.139 & $1.40(5.79)$ \\
\hline Occiput-C7 Sagittal Cobb angle (degrees) & $-44.94(11.0)$ & $-51.92(9.89)$ & 0.000 & $6.98(8.44)$ \\
\hline C1-C2 Sagittal Cobb angle (degrees) & $-33.87(8.65)$ & $-33.95(14.78)$ & 0.963 & $0.09(11.39)$ \\
\hline C2-C7 a Sagittal Cobb angle (degrees) & $-4.73(12.96)$ & $-8.58(12.81)$ & 0.041 & $3.86(11.23)$ \\
\hline T1 tilt (degrees) & $23.87(8.82)$ & $28.90(8.64)$ & 0.000 & $-5.03(6.28)$ \\
\hline C2-C7 Sagittal Vertical Axis (mm) & $15.28(14.36)$ & $20.04(18.47)$ & 0.049 & $-4.76(14.18)$ \\
\hline C1-C7 Sagittal Vertical Axis (mm) & $22.14(18.34)$ & $26.95(21.02)$ & 0.090 & $-4.80(16.99)$ \\
\hline Center of Gravity-C7 Sagittal Vertical Axis (mm) & $14.23(14.84)$ & $17.06(14.80)$ & 0.304 & $-2.83(16.03)$ \\
\hline Chin-brow-vertical angle (degrees) & $-62.79(5.17)$ & $-61.93(4.42)$ & 0.098 & $-0.86(2.16)$ \\
\hline
\end{tabular}


radiograph were similar, except for the $\mathrm{C} 0-\mathrm{C} 7$ sagittal Cobb and the T1 tilt. Whether these differences have any clinical relevance needs to be further studied. Especially since the only study published looking at cervical sagittal parameters and clinical outcomes showed weak correlations between patient reported outcomes and C2C7SVA and COG-C7 SVA [29]. In certain patients, dedicated cervical spine films may still be indicated to rule out malignancy or other pathologies. Further studies with multiple observers should also be done to determine the reliability of these cervical measures as determined from a 36-inch radiograph and dedicated cervical spine film.

\section{Conclusions}

A dedicated cervical spine radiograph may not be necessary to evaluate the sagittal parameters of the cervical spine when a full-length 36-inch radiograph has already been obtained.

\section{Competing interests}

LYC-Member, Editorial Advisory Board, Spine and Spine Journal; Institutional Review Board Member, University of Louisville; Global Evidence Advisory Board Member, Medtronic 2012, 2013; Research Committee Member, SRS; received research grants from Norton Healthcare and AOSpine paid directly to SRS 20102011; receives research funds from OREF, 2013-present; received research grant from Norton Healthcare, 2013; receives SRS Research Funding, 2013-present; receives research funding from the Norton Healthcare James R. Petersdorf Fund 2015; received funds for travel from Association for Collaborative Spine Research the University of Southern Denmark; University of Louisville; Honoraria for participation in Review Panels NIH, CTF, and Global Evidence Advisory Board, Medtronic. Nuvasive provided funds directly to database company. No funds are paid directly to Individual or Individual's Institution 06/2012-04/2015.

CLS has nothing to disclose.

JRD — Board member, SRS; receives consulting fees from Medtronic and DePuy; receives payments for lectures from Medtronic, DePuy and Norton Healthcare; holds patents from and receives royalties from Medtronic; is on the editorial review board of JBJS Highlights, Spine, Spine Deformity, JAAOS and Global Spine. Medtronic provided funds directly to database company. No funds were paid directly to Individual or Individual's Institution 01/2002 to 09/2009. Nuvasive provided funds directly to database company. No funds are paid directly to Individual or Individual's Institution 06/2012-04/2015.

SDG - is an employee of Norton Healthcare; received research grants from Norton Healthcare; holds patents from and receives royalties from Medtronic. Medtronic provided funds directly to database company. No funds were paid directly to Individual or Individual's Institution 01/2002 to 09/2009. Nuvasive provided funds directly to database company. No funds are paid directly to Individual or Individual's Institution 06/2012-04/2015.

\section{Authors' contributions}

LYC - acquisition of data, analysis and interpretation of data drafting of the manuscript, critical revision of the manuscript, CLS-acquisition of data, analysis and interpretation of data, critical revision of the manuscript, JRD - conception and design, analysis and interpretation of data, acquisition of data, critical revision of the manuscript, SDG - conception and design, analysis and interpretation of data, acquisition of data, critical revision of the manuscript. All authors read and approved the final manuscript.

\section{Acknowledgements}

No other person aside from the authors made substantial contributions to conception, design, acquisition of data, or analysis and interpretation of data, or was involved in drafting the manuscript or revising it critically for important intellectual content. No funding was received for the design, in the collection, analysis, and interpretation of data; in the writing of the manuscript; and in the decision to submit the manuscript for publication. No language editor or scientific (medical) writer was involved in the preparation of the manuscript

\section{Author details}

${ }^{1}$ Norton Leatherman Spine Center, 210 East Gray Street, Suite 900, Louisville, KY 40202, USA. ${ }^{2}$ Central States Orthopedic Specialists, William Medical Building, 6585 S. Yale Ave. Ste. 200, Tulsa, OK 74136, USA.

Received: 14 December 2015 Accepted: 18 March 2016

Published online: 07 April 2016

\section{References}

1. Koller H, Pfanz C, Meier O, Hitzl W, Mayer M, Bullmann V, Schulte TL. Factors influencing radiographic and clinical outcomes in adult scoliosis surgery: a study of 448 European patients. Eur Spine J. 2016:25(2):532-548.

2. Sciubba DM, Scheer JK, Yurter A, Smith JS, Lafage V, Klineberg E, Gupta M, Eastlack R, Mundis GM, Protopsaltis TS, Blaskiewicz D, Kim HJ, Koski T, Kebaish K, Shaffrey Cl, Bess S, Hart RA, Schwab F, Ames CP; the International Spine Study Group (ISSG). Patients with spinal deformity over the age of 75 : a retrospective analysis of operative versus non-operative management. Eur Spine J. 2015 Feb 6 [Epub ahead of print].

3. Smith JS, Shaffrey Cl, Lafage V, Schwab F, Scheer JK, Protopsaltis T, Klineberg E, Gupta M, Hostin R, Fu KG, Mundis GM Jr, Kim HJ, Deviren V, Soroceanu A, Hart RA, Burton DC, Bess S, Ames CP; International Spine Study Group. Comparison of best versus worst clinical outcomes for adult spinal deformity surgery: a retrospective review of a prospectively collected, multicenter database with 2-year follow-up. J Neurosurg Spine. 2015;5:1-11.

4. Berjano $P$, Langella F, Ismael MF, Damilano M, Scopetta S, Lamartina C. Successful correction of sagittal imbalance can be calculated on the basis of pelvic incidence and age. Eur Spine J. 2014;23 Suppl 6:587-96.

5. De Giorgi S, De Giorgi G, Borracci C, Tafuri S, Piazzolla A, Moretti B. Adult scoliosis: age-related deformity and surgery. Eur Spine J. 2014;23 Suppl 6:597-603.

6. Diebo BG, Ferrero E, Lafage R, Challier V, Liabaud B, Liu S, Vital JM, Errico TJ, Schwab FJ, Lafage V. Recruitment of compensatory mechanisms in sagittal spinal malalignment is age and regional deformity dependent: a full-standing axis analysis of key radiographical parameters. Spine (Phila Pa 1976). 2015;40(9):642-9.

7. Roussouly P, Labelle H, Rouissi J, Bodin A. Pre- and post-operative sagittal balance in idiopathic scoliosis: a comparison over the ages of two cohorts of 132 adolescents and 52 adults. Eur Spine J. 2013;22 Suppl 2:S203-15.

8. Blondel B, Schwab F, Bess S, Ames C, Mummaneni PV, Hart R, Smith JS, Shaffrey Cl, Burton D, Boachie-Adjei O, Lafage V. Posterior global malalignment after osteotomy for sagittal plane deformity: it happens and here is why. Spine (Phila Pa 1976). 2013;38(7):E394-401.

9. Boissière L, Vital JM, Aunoble S, Fabre T, Gille O, Obeid I. Lumbo-pelvic related indexes: impact on adult spinal deformity surgery. Eur Spine J. 2015;24(6):1212-8.

10. Larson AN, Fletcher ND, Daniel C, Richards BS. Lumbar curve is stable after selective thoracic fusion for adolescent idiopathic scoliosis: a 20-year follow-up. Spine (Phila Pa 1976). 2012;37(10):833-9.

11. Peelle MW, Boachie-Adjei O, Charles G, Kanazawa Y, Mesfin A. Lumbar curve response to selective thoracic fusion in adult idiopathic scoliosis. Spine J. 2008;8(6):897-903.

12. Aykac B, Ayhan S, Yuksel S, Guler UO, Pellise F, Alanay A, Perez-Grueso FJ, Acaroglu E; ESSG European Spine Study Group. Sagittal alignment of cervical spine in adult idiopathic scoliosis. Eur Spine J. 2015;24(6):1175-82.

13. Canavese F, Turcot K, De Rosa V, de Coulon G, Kaelin A. Cervical spine sagittal alignment variations following posterior spinal fusion and instrumentation for adolescent idiopathic scoliosis. Eur Spine J. 2011;20(7):1141-8.

14. Hwang SW, Samdani AF, Tantorski M, Cahill P, Nydick J, Fine A, Betz RR, Antonacci MD. Cervical sagittal plane decompensation after surgery for adolescent idiopathic scoliosis: an effect imparted by postoperative thoracic hypokyphosis. J Neurosurg Spine. 2011;15(5):491-6. doi:10.3171/2011.6.SPINE1012. Epub 2011 Jul 29

15. Ofiram E, Garvey TA, Schwender JD, Wroblewski JM, Winter RB. Cervical degenerative changes in idiopathic scoliosis patients who underwent long fusion to the sacrum as adults: incidence, severity, and evolution. J Orthop Traumatol. 2009;10(1):27-30.

16. Oh T, Scheer JK, Eastlack R, Smith JS, Lafage V, Protopsaltis TS, Klineberg E, Passias PG, Deviren V, Hostin R, Gupta M, Bess S, Schwab F, Shaffrey Cl, Ames CP;International Spine Study Group. Cervical compensatory alignment changes following correction of adult thoracic deformity: a multicenter experience in 57 patients with a 2-year follow-up. J Neurosurg Spine. 2015;22(6):658-65. 
17. Passias PG, Soroceanu A, Smith J, Boniello A, Yang S, Scheer JK, Schwab F, Shaffrey C, Kim HJ, Protopsaltis T, Mundis G, Gupta M, Klineberg E, Lafage V, Ames C; International Spine Study Group. Postoperative cervical deformity in 215 thoracolumbar patients with adult spinal deformity: prevalence, risk factors, and impact on patient-reported outcome and satisfaction at 2-year follow-up. Spine(Phila Pa 1976). 2015;40(5):283-91.

18. Protopsaltis TS, Scheer JK, Terran JS, Smith JS, Hamilton DK, Kim HJ, Mundis GM Jr, Hart RA, McCarthy IM, Klineberg E, Lafage V, Bess S, Schwab F, Shaffrey Cl, Ames CP; International Spine Study Group. How the neck affects the back:changes in regional cervical sagittal alignment correlate to HRQOL improvement in adult thoracolumbar deformity patients at 2-year follow-up. J Neurosurg Spine. 2015;15:1-6.

19. Schairer WW, Carrer A, Lu M, Hu SS. The increased prevalence of cervical spondylosis in patients with adult thoracolumbar spinal deformity. I Spinal Disord Tech. 2014:27(8):E305-8.

20. Weber MH, Hong CH, Schairer WW, Takemoto S, Hu SS. The concomitance of cervical spondylosis and adult thoracolumbar spinal deformity. Evid Based Spine Care J. 2014:5(1):6-11.

21. Ames CP, Blondel B, Scheer JK, Schwab FJ, Le Huec JC, Massicotte EM, Patel AA, Traynelis VC, Kim HJ, Shaffrey Cl, Smith JS, Lafage V. Cervical radiographical alignment: comprehensive assessment techniques and potential importance in cervical myelopathy. Spine (Phila Pa 1976). 2013;38(22 Suppl 1):S149-60

22. Simony A, Jensen KE, Christensen SB, Carreon LY, Andersen MO. Incidence of cancer and infertility in AIS patients treated 25 years prior. Minneapolis: Proceedings of the Scoliosis Research Society 50th Annual Meeting and Course; 2015. p. 179-80.

23. Horton WC, Brown CW, Bridwell KH, Glassman SD, Suk SI, Cha CW. Is there an optimal patient stance for obtaining a lateral 36 "radiograph? A critical comparison of three techniques. Spine (Phila Pa 1976). 2005;30(4):427-33.

24. Franzblau AN. A Primer of Statistics for Non-statisticians. Harcourt, Brace: New York; 1958.

25. Glassman SD, Bridwell K, Dimar JR, Horton W, Berven S, Schwab F. The impact of positive sagittal balance in adult spinal deformity. Spine (Phila Pa 1976). 2005;30(18):2024-9.

26. Schwab FJ, Blondel B, Bess S, Hostin R, Shaffrey Cl, Smith JS, Boachie-Adjei O, Burton DC, Akbarnia BA, Mundis GM, Ames CP, Kebaish K, Hart RA, Farcy JP, Lafage V; International Spine Study Group (ISSG). Radiographical spinopelvic parameters and disability in the setting of adult spinal deformity: a prospective multicenter analysis. Spine (Phila Pa 1976). 2013;38(13):E803-12.

27. Smith JS, Shaffrey Cl, Lafage V, Blondel B, Schwab F, Hostin R, Hart R, O'Shaughnessy B, Bess S, Hu SS, Deviren V, Ames CP; International Spine Study Group. Spontaneous improvement of cervical alignment after correction of global sagittal balance following pedicle subtraction osteotomy. J Neurosurg Spine. 2012;17(4):300-7.

28. Glassman SD, Carreon LY, Schwab FJ, Shaffrey Cl, Hu SS, Bridwell KH. The Impact of Adult Scoliosis on the Cervical Spine. Kyoto: Paper presented at the Scoliosis Research Society Annual Meeting; 2010.

29. Tang JA, Scheer JK, Smith JS, Deviren V, Bess S, Hart RA, Lafage V, Shaffrey CI, Schwab F, Ames CP; ISSG. The impact of standing regional cervical sagittal alignment on outcomes in posterior cervical fusion surgery. Neurosurgery. 2012;71(3):662-9.

\section{Submit your next manuscript to BioMed Central and we will help you at every step:}

- We accept pre-submission inquiries

- Our selector tool helps you to find the most relevant journal

- We provide round the clock customer support

- Convenient online submission

- Thorough peer review

- Inclusion in PubMed and all major indexing services

- Maximum visibility for your research

Submit your manuscript at www.biomedcentral.com/submit

C Biomed Central 